\title{
Gérard de Nerval, Voyages en Europe
}

\section{Lise Sabourin}

\section{(2) OpenEdition}

\section{Journals}

\section{Édition électronique}

URL : http://journals.openedition.org/studifrancesi/2212

DOI : 10.4000/studifrancesi.2212

ISSN : 2427-5856

\section{Éditeur}

Rosenberg \& Sellier

\section{Édition imprimée}

Date de publication : 1 avril 2014

Pagination : 167

ISSN : 0039-2944

\section{Référence électronique}

Lise Sabourin, « Gérard de Nerval, Voyages en Europe », Studi Francesi [En ligne], 172 (LVIII | I) | 2014 mis en ligne le 01 avril 2014, consulté le 18 septembre 2020. URL : http://journals.openedition.org/ studifrancesi/2212 ; DOI : https://doi.org/10.4000/studifrancesi.2212

\section{Ce document a été généré automatiquement le 18 septembre 2020.}

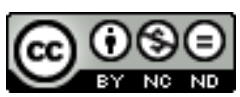

Studi Francesi è distribuita con Licenza Creative Commons Attribuzione - Non commerciale - Non opere derivate 4.0 Internazionale. 


\title{
Gérard de Nerval, Voyages en Europe
}

\author{
Lise Sabourin
}

\section{RÉFÉRENCE}

GÉRARD DE NERVAL, Voyages en Europe, textes établis, présentés et commentés par Michel BRIX et Hisashi MIZUNO, Paris, Éditions du Sandre, 2011, pp. 388.

1 Nerval, que Sainte-Beuve qualifie malicieusement de «commis-voyageur littéraire de Paris à Munich», est effectivement en «vol perpétuel» ainsi que le reconnaît Gautier et comme permet de l'apprécier la chronologie de ses voyages présentée en fin de volume (pp. 381-385).

2 Après son voyage en Provence et en Italie jusqu'à Naples à l'automne 1834, il s'élance vers la Belgique en juillet 1836 en compagnie de son ami «Théo» qui narre leurs pérégrinations pour «La Chronique de Paris» balzacienne de septembre à décembre 1836. Sans doute Gérard décide-t-il alors de raconter lui aussi ses impressions, ce qu'il fait pour la première fois lors de son voyage pour rejoindre Dumas à Francfort en aoûtseptembre 1838 en vue de préparer Léo Bruckart. C'est en piéton, selon son choix favori, mais aussi vu la maigreur de sa bourse, qu'il rentre de sa découverte de Mannheim et Heidelberg par Bade et Strasbourg (pp. 45-76). Aussi dès novembre 1839 imagine-t-il de se faire attribuer une «mission diplomatique» pour retourner examiner l'image de la France dans l'opinion allemande et autrichienne (pp. 77-86). Mais la chute du ministère Guizot le surprend à Vienne en situation délicate comme le montrera Pandora et l'oblige à rentrer «à pied en partie», «dépenaillé» et affamé en mars 1840 (pp. 87-170). Il rêve pourtant encore d'être soutenu par le ministère Thiers, qui chute lui aussi, alors qu'il est en Belgique de mi-octobre 1840 à janvier 1841 (pp. 171-196). Le récit de voyage change désormais de statut pour Nerval: de sa description pleine de fantaisie réaliste, il passe à une fiction épistolaire d'un nouveau ton, notamment sur son amour de Vienne (pp. 197-220). D'autres secours ministériels lui permettront le périple en Orient (hors corpus en ce volume) de 1842 à janvier 1844 où il rejoint par la Grèce (pp. 243-276) l'Italie, notamment Naples (pp. 277-302), avant de repartir en septembre à Bruxelles 
avec Houssaye (pp. 221-242). Deux voyages londoniens sont effectués durant l'été 1846, par Anvers et retour au fil de la Moselle de Coblence à Metz, et au printemps 1849 (pp. 303-324). Après un nouveau tour en Autriche en 1849 (pp. 325-340), flatté par l'appréciation de Goethe sur sa traduction de Faust, Nerval se rend aux fêtes de Weimar organisées par Liszt en août 1850, où il est accueilli en ami quoique arrivé en retard vu son passage par Bruxelles et Francfort (pp. 341-380). De nouveau, la Belgique et la Hollande en mai 1852, puis une dernière fois l'Allemagne en juin-juillet 1854: c'est bien un voyageur-né, apte à s'adapter aux mœurs et à découvrir les paysages, un marcheur infatigable que ce chroniqueur reconnu en son temps.

3 Michel BRIX et Hisashi MIZUNO ont choisi de donner la version originale de tous ces textes, souvent modifiés lors de leurs versions successives. Ils soulignent dans leur introduction (pp. 7-42) l'originalité de la position nervalienne: fuyant dès le début la description des monuments et des sites pour s'écarter des guides utilisés par les voyageurs, Gérard rend ses sensations de flâneur, attaché au goût des détails et habile à manier le paradoxe; après 1841, il laisse même la parole à un narrateur enjoué, volontiers onirique, qui devient un véritable personnage littéraire, porteur de sa libre imagination, pour témoigner de la pantomime du monde, tout en laissant émerger ses réflexions sur les mœurs étrangères ou ses engouements personnels pour la musique et les arts. 